\title{
Do septal lesions eliminate behavioral control by an autocontingency?
}

\author{
HANK DAVIS, THOM HERRMAN, and LACHLAN MacFADDEN \\ University of Guelph, Guelph, Ontario, Canada N1G 2 WI \\ and \\ PAUL ELLEN \\ Georgia State University, Atlanta, Georgia 30303
}

\begin{abstract}
Rats were trained to leverpress for food and then exposed to unsignaled shock deliveries. Responding was initially suppressed throughout the session, but showed gradual recovery when subjects detected that shocks were separated by a minimum 3-min interval (an "if-shockthen-no-shock" autocontingency). Autocontingency control, expressed as a ratio of accelerated responding following shock offset, appeared to be eliminated in Experiment 1 in subjects receiving septal damage. In order to examine the effects of septal lesions on control by the autocontingency, per se, without interference from response rate increases produced by septal damage, atropine sulfate was administered to all subjects in Experiment 2. The return to lower response rates under atropine made it clear that septal lesions had not eliminated retention of the autocontingency, but rather had masked its control over behavior by increasing the rate of baseline responding. The importance of an appropriate behavioral baseline for demonstrating stimulus or schedule control is discussed with regard to interpreting behavior change produced by septal damage.
\end{abstract}

The present research examines the question of whether a septal lesion disrupts control over leverpressing behavior previously established by an autocontingency.

The properties of autocontingencies were first described by Davis, Memmott, and Hurwitz (1975), who demonstrated that rats which received unpredictable shock deliveries while working for food soon stopped leverpressing altogether. Response rates showed eventual recovery, however, if the animal was able to detect subtle regularities in the pattern of shock delivery and thereby define "safe periods" for responding. For example, a minimum 3-min intershock interval in an otherwise random pattern of shock delivery provides a brief period of relative "safety" which leads to accelerated responding following each shock delivery. This "if-shock-then-noshock" relationship is termed an autocontingency, and is distinguished from traditional contingencies in which shock is predicted by a physically different event (e.g., if-tone-then-shock).

Our initial work on autocontingencies followed the basic model of conditioned suppression; i.e., the rate of response on a previously established operant baseline is differentially affected by unmodifiable delivery of an aversive event (Davis, 1968; Estes \& Skinner, 1941). A number of experiments have dealt with the

This research was supported in part by Grant A0673 to Hank Davis from the National Research Council of Canada. The authors thank Ronald Doucette for his skillful assistance. Reprints may be obtained from Hank Davis, Department of Psychology, University of Guelph, Guelph, Ontario, Canada N1G 2 W1. effects of septal lesions on behavior controlled by the conditioned suppression procedure. Although there is considerable variability in procedures as well as outcomes, a strong suggestion emerges that septal lesions may reduce the degree of response suppression obtained to a signal which is paired with shock (e.g., Brady \& Nauta, 1955; Harvey, Lints, Jacobson, $\&$ Hunt, 1965). If this is indeed the case, the question remains whether septal damage might also attenuate control established by an autocontingency, in which (1) conditioned acceleration, rather than suppression, is used to indicate behavior control, and (2) the contingency by which shock is predicted is arguably more subtle insofar as no exteroceptive signal is involved.

\section{EXPERIMENT 1}

In Experiment 1, rats were exposed to an autocontingency under which a varying number of uncontrollable shocks were presented while subjects leverpressed for food. Although no exteroceptive signal preceded shock delivery, shocks were separated by a minimum 3-min interval. When control by this "if-shock-then-no-shock" autocontingency was in evidence (i.e., when response rates were elevated in the 1-min period following shock offset), half the subjects received total septal damage. Following recovery from surgery, all subjects were reintroduced to the autocontingency procedure and the behavior of the operated subjects was compared to that of surgical control animals. 


\section{Method}

Subjects. Ten male Long-Evans rats, approximately 120 days old at the start of training, served as subjects. All animals were maintained at approximately $80 \%$ of their free-feeding weights and were given free access to water in their home cages.

Apparatus. The subjects were run in a commercially available operant test chamber (Campden Instruments Co.). Forty-fivemilligram Noyes pellets served as reinforcement. The floor of the test chamber consisted of 16 stainless steel grids, $.9 \mathrm{~cm}$ in diameter and spaced $.9 \mathrm{~cm}$ apart from edge to edge. A constant current shock generator (Campden Instruments Co.) delivered scrambled shock to the grids. Shock deliveries were calibrated at $0.8 \mathrm{~mA}$ for $1 \mathrm{sec}$.

Procedure. All subjects were initially trained to leverpress for food and then exposed to a daily 30 -min session on a variable interval (VI) 30-sec schedule. When visual inspection of the cumulative response records revealed that response rates had stabilized on the schedule, exposure to the autocontingency was begun. Subjects were given 35 daily sessions in which a sequence of shocks (range 1-5), which varied daily in time of delivery, was programmed to occur while the subject worked for food. No warning signals were presented prior to shock, but a minimum of 3 min intervened between shock deliveries.

Following exposure to this autocontingency, the subjects were randomly assigned to the septal damage or surgical control group. All subjects were anesthetized with sodium pentobarbital (Nembutal, $60 \mathrm{mg} / \mathrm{ml}$ solution) at a dosage level of $36 \mathrm{mg} / \mathrm{kg}$. A Radionics RFG-4 lesion device was used with the RF electrode lowered to De Groot coordinates A/P, +7.5; L, 0; D/V, +6.5 from stereotaxic zero. For the septal-lesion group, the tip of the electrode was heated to $80^{\circ} \mathrm{C}$ for $20 \mathrm{sec}$. Five days following surgery, all subjects were reexposed to the autocontingency procedure for 20 sessions.

\section{Results and Discussion}

Subjects receiving septal lesions sustained bilateral destruction of the medial and lateral septal nuclei with less than $10 \%$ bilateral damage to the caudate nucleus, fornix, and corpus callosum (see Figure 1). The results of the septal lesion and surgical control procedures on behavior control by the autocontingency are presented in Table 1 . The effects of exposure to the autocontingency are expressed in terms of an acceleration ratio of the form $\mathbf{A} / \mathbf{A}+\mathbf{B}$, where $\mathbf{A}=$ mean response rate in the 1 -min period. following each shock and $\mathrm{B}=$ mean response rate in remaining minutes of the session. Elevated response rates in the $1 \mathrm{~min}$ following shock offset are expressed as ratio values greater than .50. Lack of autocontingency control (i.e., no change in response rate following shock offset) results in ratios which approximate .50 .

Prior to surgery, all subjects revealed autocontingency control averaging .66. These values are similar to results previously reported (Davis et al., 1975), and reflect accelerated responding in the brief periods of "safety" following each shock offset. Following surgery, however, there was a virtual loss of autocontingency control in septal animals $[\mathrm{t}(4)=4.21$, $\mathrm{p}<.02$ ], whereas the behavior of control subjects appeared unaffected.

An examination of the baseline response rates upon which these ratios are based reveals that a major effect of the septal lesion was to increase responding

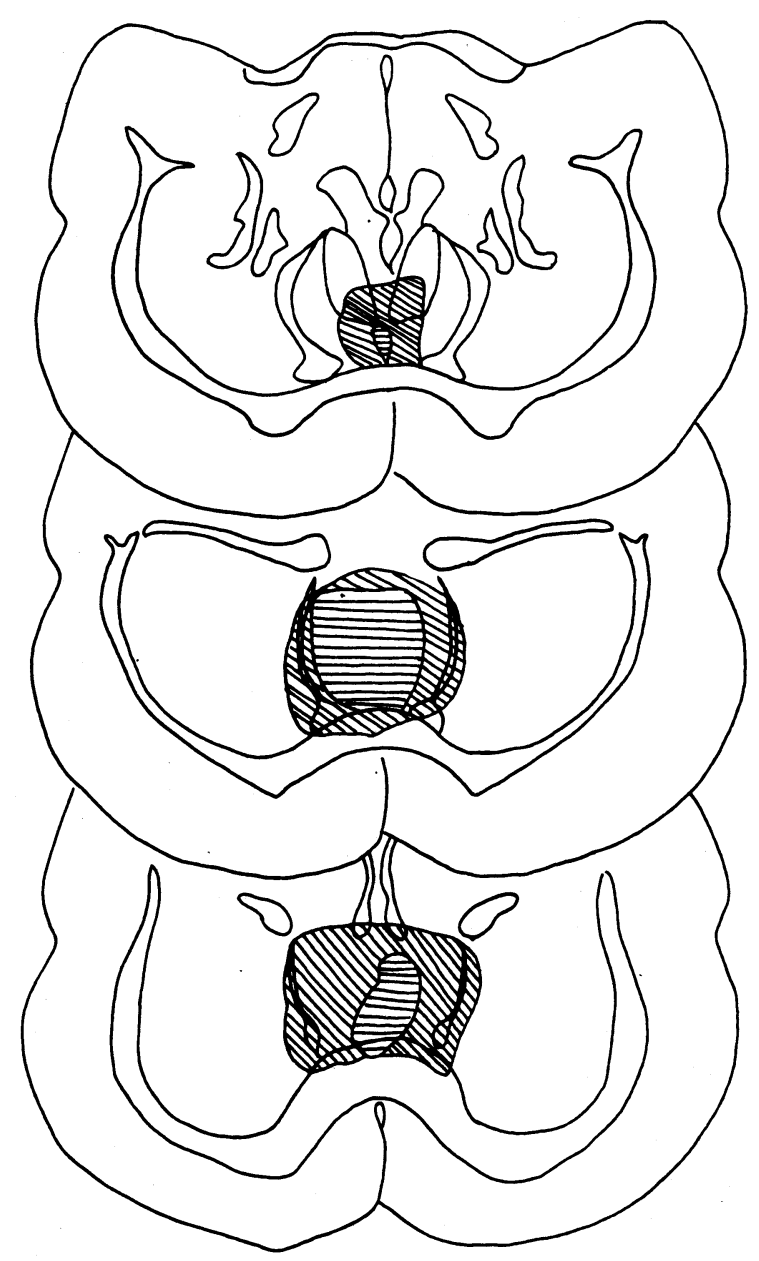

Figure 1. Serial reconstructions of septal lesions in the coronal plane. Horizontal striped areas represent minimal destruction and oblique areas represent maximal destruction. (Plates modeled after Köning \& Klippel, 1963.)

Table 1

Acceleration Ratios* Expressing Degree of Autocontingency Control Obtained During Final Five Presurgery Sessions and Final Five Postsurgery Sessions

\begin{tabular}{ccc} 
& Presurgery & Postsurgery \\
\hline Septal & & \\
No. 1 & .66 & .49 \\
No. 2 & .60 & .49 \\
No. 3 & .71 & .45 \\
No. 4 & .76 & .52 \\
No. 5 & .59 & .53 \\
Mean & .66 & .50 \\
Control** & & \\
No. 6 & .68 & .69 \\
No. 7 & .59 & .58 \\
No. 8 & .69 & .68 \\
No. 9 & .63 & .65 \\
Mean & .65 & .65 \\
\hline
\end{tabular}

*See text for explanation.

**One subject in the control group died following surgery. 
throughout the session. While response rates remained virtually unchanged for control subjects $(\bar{X}=5.5$ $\mathrm{Rs} / \mathrm{min}$ pre- vs. $5.0 \mathrm{Rs} / \mathrm{min}$ postsurgery), the septal lesions increased baseline responding substantially $\overline{\mathrm{X}}=3.9 \mathrm{Rs} / \mathrm{min}$ pre- vs. $20.0 \mathrm{Rs} / \mathrm{min}$ postsurgery. It is entirely possible, therefore, that the loss of autocontingency control, as evidenced in acceleration ratios, may be an artifact of the increased responding produced by septal damage.

\section{EXPERIMENT 2}

Experiment 2 was performed to determine whether septal damage resulted directly in the loss of autocontingency control observed in Experiment 1, or whether increased response rates produced by this damage might have masked conditioned acceleration, from which autocontingency control is inferred.

In order to examine this question, both groups of subjects run in Experiment 1 were given intraperitoneal injections of atropine sulfate, a cholinergic blocking agent previously demonstrated to suppress increased rates of responding produced by septal lesions (Ellen, Aitken, Sims, \& Stahl, 1975). The question of whether septal damage resulted in loss of autocontingency control could then be tested independently of septal lesion-induced changes in baseline rate.

\section{Method}

Subjects. The subjects were the same as those employed in Experiment 1.

Apparatus. The apparatus was the same as in Experiment 1.

Procedure. Following the final test session in Experiment 1, all subjects were exposed to the following sequence of saline (control) or atropine sulfate injections prior to each autocontingency session. Days 1, 2, saline; Day 3, atropine; Days 4, 5, saline; Day 6, atropine; Days 7, 8, saline. The subjects were injected intraperitoneally either with atropine sulfate $(6 \mathrm{mg} / \mathrm{kg})$ or with saline $45 \mathrm{~min}$ prior to being placed in the test chamber. All subjects were sacrificed at the end of testing and their brains were removed for histological examination. This consisted of a saline, followed by a $10 \%$ Formaline in saline perfusion, paraffin mounting, and thionin staining of every 20 th section cut at $15 \mu$.

\section{Results and Discussion}

The results of atropine sulfate and saline (control) injections on autocontingency control are reported in Table 2. Because acceleration ratios were consistent across drug treatment days, the results are expressed in terms of an atropine mean and a saline mean. As expected, acceleration ratios obtained under saline did not differ from postsurgical values reported in Experiment 1. The effects of atropine on this measure, however, were quite marked. Pronounced increases in acceleration ratios occurred in both groups under exposure to atropine, although the increase over saline values reached significance only in the septal damage group $[\mathrm{t}(4)=4.35, \mathrm{p}<.02]$. In some cases, acceleration ratios obtained under atropine exceeded values observed prior to surgery in Experiment 1.
Table 2

Acceleration Ratios* Expressing Degree of Autocontingency Control Obtained in Final Five Sessions Following Surgery, and Following Injections of Atropine Sulfate and Saline

\begin{tabular}{cccc}
\hline & Postsurgery & Saline & Atropine \\
\hline Septal & & & \\
No. 1 & .49 & .53 & .67 \\
No. 2 & .49 & .50 & .55 \\
No. 3 & .45 & .47 & .72 \\
No. 4 & .52 & .55 & .79 \\
No. 5 & .53 & .52 & .83 \\
Mean & .50 & .51 & .71 \\
Control** & & & \\
No. 1 & .69 & .70 & .86 \\
No. 2 & .58 & .56 & .73 \\
No. 3 & .68 & .75 & .83 \\
No. 4 & .65 & .60 & .59 \\
Mean & .65 & .65 & .75 \\
\hline
\end{tabular}

* See text for explanation.

**One subject in the control group died following surgery.

The effect of atropine on acceleration ratios is almost certainly due to the substantial decline in baseline response rates, from which acceleration ratios are computed. For example, mean baseline responding in animals with septal lesions was reduced from $22 \mathrm{Rs} / \mathrm{min}$ during saline sessions to a mean of $2.8 \mathrm{Rs} / \mathrm{min}$ under atropine. Similarly, baseline responding in control animals, which was initially lower $(\bar{X}=4.5 \mathrm{Rs} / \mathrm{min}$ under saline $)$, was reduced still further under atropine to $2.3 \mathrm{Rs} / \mathrm{min}$. Thus, atropine not only reasserted autocontingency control in subjects with lesions, but increased acceleration ratios in control animals as well.

\section{GENERAL DISCUSSION}

Autocontingency control, expressed as a ratio of accelerated responding following shock offset, was not evident in subjects who underwent septal lesions. In order to investigate the nature of this deficit, atropine sulfate was administered to all subjects to determine whether control had been abolished or was masked by exaggerated lesion-induced baseline responding. The reduction in response rates produced by atropine and the reappearance of acceleration ratios make it clear that septal damage had masked, rather than eliminated, previously established control by the autocontingency.

The importance of a relatively suppressed baseline in revealing conditioned acceleration has previously been demonstrated by Davis, Memmott, and Hurwitz (1976). These results are similar to a recent report by Ellen et al. (1975) that apparent loss of behavior control by rats with septal damage on a DRL schedule could be reasserted by atropine. Collectively, these findings suggest that an important element in demonstrating schedule or stimulus control is the establish- 
ment of an appropriate behavioral baseline, which may be a primary casualty of septal damage.

It remains to be demonstrated whether septal damage would affect acquisition of control by an autocontingency. A recent study bears on this question. Hobbs (1975) reported that rats with septal damage could be successfully trained under a conditioned suppression procedure, although their baseline response rates remained higher than normals'. It should be stressed, however, that ratio measures of conditioned suppression, unlike conditioned acceleration, are improved when baseline responding is increased.

\section{REFERENCES}

BRADY, J. V., \& NAUTA, W. Subcortical mechanisms in emotional behavior: The duration of affective changes following septal and habenular lesions in the albino rat. Journal of Comparative and Physiological Psychology, 1955, 48, 412-420.

Davis, H. Conditioned suppression: A survey of the literature. Psychonomic Monograph Supplements, 1968, 2, 283-291.
Davis, H., Memmotr, J., \& HuRwitz, H. M. B. Autocontingencies: A model for subtle behavioral control. Journal of Experimental Psychology: General, 1975, 104, 169-188.

Davis, H., Memmott, J., \& HuRwitz, H. M. B. Effects of signals preceding and following shock on baseline responding during a conditioned suppression procedure. Journal of the Experimental Analysis of Behavior, 1976, 25, 263-277.

Ellen, P., Aitken, W. C., Sims, T., \& Stahl, J. Cholinergic blockade, septal lesions, and DRL performance in the rat. Journal of Comparative and Physiological Psychology, 1975, 89, 409-420.

Estes, W. K., \& Skinner, B. F. Some quantitative properties of anxiety. Journal of Experimental Psychology, 1941, 29, 390-400.

HaRvey, J. A., Lints, C. E., Jacobson, L. E., \& Hunt, H. F. Effects of lesions in the septal area on conditioned fear and discriminated instrumental punishment in the albino rat. Journal of Comparative and Physiological Psychology, 1965, 59, 37-48.

Hовв S, S. H. Conditioned suppression by rats with septal lesions. IRCS Medical Science: Neurobiology and Neurophysiology; Psychology, 1975, 3, 354.

Köning, J. A., \& Klippel, R. A. The rat brain: A stereotoxic atlas. New York: Williams \& Wilkins, 1963.

(Received for publication March 14, 1977; revision accepted May 24, 1977.) 